\title{
Use of Outpatient Rehabilitation Among Adult Stroke Survivors - 20 States and the District of Columbia, 2013, and Four States, 2015
}

\author{
Carma Ayala, $\mathrm{PhD}^{1}$; Jing Fang, $\mathrm{MD}^{1}$; Cecily Luncheon, MD, DrPH; Sallyann Coleman King, $\mathrm{MD}^{1}$; Tiffany Chang, $\mathrm{MPH}^{1}$; \\ Matthew Ritchey, DPT ${ }^{1}$; Fleetwood Loustalot, $\mathrm{PhD}^{1}$
}

Stroke is a leading cause of mortality and disability in the United States $(1,2)$. Approximately 800,000 American adults experience a stroke each year $(2,3)$. Currently, approximately 6 million stroke survivors live in the United States (2). Participation in stroke rehabilitation (rehab), which occurs in diverse settings (i.e., in-hospital, postacute care, and outpatient settings), has been determined to reduce stroke recurrence and improve functional outcomes and quality of life $(3,4)$. Despite longstanding national guidelines recommending stroke rehab, it remains underutilized, especially in the outpatient setting. Professional associations and evidence-based guidelines support the increasing stroke rehab use in health systems and are promoted by the public health community (3-6). An analysis of 2005 Behavioral Risk Factor Surveillance System (BRFSS) data revealed that $30.7 \%$ of stroke survivors reported participation in outpatient rehab for stroke after hospital discharge in 21 states and the District of Columbia (DC) (7). To update these estimates, 2013 and 2015 BRFSS data were analyzed to assess outpatient rehab use among adult stroke survivors. Overall, outpatient rehab use was 31.2\% (20 states and DC) in 2013 and $35.5 \%$ (four states) in 2015. Disparities were evident by sex, race, Hispanic origin, and level of education. Focused attention on system-level interventions that ensure participation is needed, especially among disparate populations with lower levels of participation.

BRFSS is a telephone survey of the noninstitutionalized U.S. population* conducted annually by all states. The cardiovascular health module, which includes questions about rehab participation, was an optional module in 2013 and 2015. In 2013, the median cardiovascular health module response rate ${ }^{\dagger}$ for 20 states ${ }^{\mathbb{S}}$ was $46.2 \%$. Among the four states $\mathbb{S}^{\mathfrak{S}}$ participating in the module in both 2013 and 2015, the response rate was $49.3 \%$ in 2013 and $51.5 \%$ in 2015.

Stroke survivors were identified by the question "Has a doctor, nurse, or other health professional ever told you that you

\footnotetext{
*https://www.cdc.gov/brfss.

$\dagger$ The overall median response rates were $46.4 \%$ in 2013 and $47.2 \%$ in 2015 for all 50 states and territories with participants in the BRFSS.

$\$$ Arizona, Arkansas, District of Columbia, Florida, Georgia, Hawaii, Iowa, Maine, Massachusetts, Minnesota, Mississippi, Missouri, Nebraska, North Carolina, North Dakota, Oklahoma, Oregon, South Carolina, Tennessee, Washington, and Wisconsin.

Georgia, Iowa, Maine, and Oregon.
}

had a stroke?" Participation in outpatient stroke rehab was only asked of those with a history of stroke and was identified among respondents who answered "yes" to the question "Following your stroke, did you go to any kind of outpatient rehabilitation?” Demographic characteristics collected included age, sex, race, Hispanic origin, education (less than high school, high school graduate, some college, or college graduate) and health insurance status. Selected cardiovascular disease risk factors included hypertension, high blood cholesterol, diabetes, obesity, and current smoking. Percentages of respondents who participated in stroke rehab were measured, overall, by demographic characteristics, by cardiovascular disease risk factors in 2013, and by state of residence, and were adjusted for age, sex, race/Hispanic origin, education, insurance status, presence of cardiovascular disease risk factors, and number of cardiovascular disease risk factors $(0,1,2,3,4$, or 5$)$. Adjusted percentages and $95 \%$ confidence intervals $(\mathrm{CIs})$ were calculated; $\mathrm{p}$-values $<0.05$ (obtained using Wald F test) were regarded as statistically significant. Statistical software was used to account for the complex sampling design.

In 2013, among 168,655 BRFSS participants, 3.3\% (95\% $\mathrm{CI}=3.1 \%-3.4 \%)$ reported a history of stroke and were classified as stroke survivors. In 2015, among 21,047 participants, $3.3 \%(95 \%$ CI $=3.0 \%-3.8 \%)$ were stroke survivors. In 2013, stroke outpatient rehab participation was 31.2\% (95\% $\mathrm{CI}=29.1 \%-33.4 \%)$ (Table 1). Men, non-Hispanic blacks, and those with a college education or higher more frequently reported participating in stroke outpatient rehab than did women, non-Hispanic others, Hispanics, and those with less than a high school education.

Total adjusted outpatient rehab participation was $31.2 \%$ in 2013 and $35.5 \%$ in 2015 (Table 2). In 2013, adjusted percentages ranged from $23.1 \%$ in Oregon to $43.6 \%$ in Minnesota. The unadjusted and adjusted percentages of stroke survivors who took part in outpatient rehab in 2015 were lowest in Maine $(28.0 \%$ and $31.3 \%$, respectively) and highest in Iowa (46.1\% and $49.8 \%$, respectively). Among the four states that included stroke outpatient rehab questions in both 2013 and 2015, the overall adjusted percentage of stroke outpatient rehab participation increased 8.3 percentage points, from $27.2 \%$ in 2013 to $35.5 \%$ in $2015(\mathrm{p}<0.05)$. 
TABLE 1. Unadjusted and adjusted* percentages of adults who survived a stroke and received outpatient stroke rehabilitation, by demographic characteristics and presence of cardiovascular disease risk factors - Behavioral Risk Factor Surveillance System (BRFSS), 20 U.S. states and the District of Columbia, 2013

\begin{tabular}{|c|c|c|c|c|c|}
\hline Characteristic & Sample size & $\begin{array}{l}\text { Unadjusted } \\
\%(95 \% \mathrm{Cl})\end{array}$ & P-value $^{\dagger}$ & $\begin{array}{l}\text { Adjusted* } \\
\%(95 \% \mathrm{Cl})\end{array}$ & P-value \\
\hline Total & 6,743 & $31.2(29.1-33.4)$ & - & $31.2(29.1-33.4)$ & $<0.001$ \\
\hline $\begin{array}{l}\text { Sex } \\
\text { Men } \\
\text { Women }\end{array}$ & $\begin{array}{l}2,616 \\
4,127\end{array}$ & $\begin{array}{l}33.7(30.4-37.2) \\
29.1(26.5-31.9)\end{array}$ & 0.038 & $\begin{array}{l}33.8(30.5-37.2) \\
29.1(26.4-31.8)\end{array}$ & 0.030 \\
\hline $\begin{array}{l}\text { Age group (yrs) } \\
18-64 \\
\geq 65\end{array}$ & $\begin{array}{l}2,468 \\
4,275\end{array}$ & $\begin{array}{l}30.9(27.6-34.4) \\
31.5(29.0-34.1)\end{array}$ & 0.798 & $\begin{array}{l}30.6(27.5-34.0) \\
31.7(29.0-34.6)\end{array}$ & 0.622 \\
\hline $\begin{array}{l}\text { Race/Ethnicity } \\
\text { White, non-Hispanic } \\
\text { Black, non-Hispanic } \\
\text { Hispanic } \\
\text { Other, non-Hispanic }\end{array}$ & $\begin{array}{r}5,132 \\
966 \\
481 \\
164\end{array}$ & $\begin{array}{l}30.3(28.0-32.7) \\
39.1(32.9-45.7) \\
26.5(20.0-34.1) \\
24.4(15.9-35.6)\end{array}$ & 0.019 & $\begin{array}{l}30.0(27.6-32.5) \\
39.8(33.6-46.2) \\
26.7(20.3-34.3) \\
25.8(17.0-37.0)\end{array}$ & 0.013 \\
\hline $\begin{array}{l}\text { Education } \\
\text { Less than high school } \\
\text { High school } \\
\text { Some college } \\
\text { College or higher }\end{array}$ & $\begin{array}{l}1,141 \\
2,255 \\
1,923 \\
1,424\end{array}$ & $\begin{array}{l}25.8(21.5-30.6) \\
32.5(28.9-36.2) \\
31.9(28.0-36.1) \\
36.3(31.5-41.2)\end{array}$ & 0.025 & $\begin{array}{l}25.7(21.4-30.5) \\
32.3(28.8-36.2) \\
32.1(28.3-36.2) \\
36.4(31.5-41.5)\end{array}$ & 0.022 \\
\hline $\begin{array}{l}\text { Insurance } \\
\text { Yes } \\
\text { No }\end{array}$ & $\begin{array}{r}6,276 \\
467\end{array}$ & $\begin{array}{l}31.6(29.5-33.7) \\
28.2(20.2-38.0)\end{array}$ & 0.492 & $\begin{array}{l}31.3(29.2-33.5) \\
30.3(21.9-40.2)\end{array}$ & 0.836 \\
\hline $\begin{array}{l}\text { CVD risk factors (no.) } \\
0 \\
1 \\
2 \\
3 \\
4 \\
5\end{array}$ & $\begin{array}{r}455 \\
1,349 \\
2,103 \\
1,805 \\
918 \\
113\end{array}$ & $\begin{array}{l}35.6(27.0-45.3) \\
29.2(24.7-34.2) \\
30.1(26.5-33.9) \\
31.5(28.0-35.2) \\
34.8(28.7-41.5) \\
21.8(12.6-35.1)\end{array}$ & 0.382 & $\begin{array}{l}35.6(27.4-40.2) \\
29.4(24.9-44.7) \\
30.3(26.7-34.4) \\
31.2(27.7-34.9) \\
34.5(28.5-41.1) \\
22.9(13.3-36.5)\end{array}$ & 0.478 \\
\hline
\end{tabular}

Abbreviations: $\mathrm{Cl}=$ confidence interval; $\mathrm{CVD}=$ cardiovascular disease.

* Adjusted for age, sex, race/ethnicity, education, insurance status, and CVD risk.

† P-values were obtained using Wald F test to identify statistically significant differences among subgroup.

$\S$ BRFSS recommends that data be suppressed when relative standard error (RSE) is $>30 \%$ or denominator $<50$; it is also suggested that if RSE is $20 \%-30 \%$, the estimates are potentially unreliable.

" Selected self-reported CVD risk factors include hypertension, high blood cholesterol, diabetes, obesity, and current smoking. Categories were assigned based on the number of risk factors present: $0,1,2,3,4$, or 5 .

\section{Discussion}

Overall, approximately one third of stroke survivors reported participating in stroke outpatient rehab. Although outpatient rehab use increased significantly in the four states that collected data in both 2013 and 2015, it remained suboptimal (3), highlighting missed opportunities to reach stroke survivors. Stroke recovery can be a long and complex process, involving multiple domains of therapy (e.g., physical, occupational, communication, and cognitive) and occurs in inpatient rehabilitation facilities, skilled nursing facilities, and outpatient rehabilitation facilities. Benefits of stroke outpatient rehab have been determined to improve patient functional status, survival, cardiovascular risk profiles, and quality of life and reduce risks for recurrent strokes and psychological or stress disorders $(3,4,8,9)$. Generally, stroke outpatient rehab participation is underutilized $(3,8)$, which this study found to be true for all subgroups and states included in the analysis. No subgroup had outpatient rehab use rates $>40 \%$, and no state had use rates $>50 \%$. Although the overall prevalence of outpatient rehab use was low, disparities in use were evident. Younger adults, women, non-Hispanic persons of other than black or white races, Hispanics, and adults with less than a high school education were less likely to use stroke outpatient rehab than their counterparts. Disparities in stroke outpatient rehab at the state level were also apparent. For example, adjusted outpatient rehab use prevalence in Minnesota (43.6\%) was almost twice that in Oregon $(23.1 \%)$.

Increasing participation in stroke outpatient rehab has been recognized as a national priority. Healthy People $2020^{* *}$ aims to increase the proportion of adult stroke survivors who are appropriately and effectively assessed and referred for rehabilitation services. The estimates from the Healthy People 2020 objective are high (90\% during 2008-2011); however, they are reflective of assessment or referral, not participation (4). Improving

\footnotetext{
** Healthy People 2020 Heart Disease and Stroke Objectives (HDS-23). https:// www.healthypeople.gov/node/4588/data_details.
} 
TABLE 2. Crude and adjusted percentages* of adults who survived a stroke and received stroke outpatient rehabilitation, by state and ascending adjusted percentage - Behavioral Risk Factor Surveillance System, 20 U.S. states and the District of Columbia (DC), 2013, and four U.S. states, 2015

\begin{tabular}{|c|c|c|c|c|c|}
\hline Year/State $^{\dagger}$ & No. & $\begin{array}{l}\text { Unadjusted } \\
\%(95 \% \mathrm{Cl})\end{array}$ & P-value ${ }^{\S}$ & $\begin{array}{l}\text { Adjusted* } \\
\%(95 \% \mathrm{Cl})\end{array}$ & P-value ${ }^{\S}$ \\
\hline \multicolumn{6}{|l|}{2013} \\
\hline Total (20 states and DC) & 6,743 & $31.2(29.1-33.4)$ & 0.003 & $31.2(29.1-33.4)$ & 0.012 \\
\hline Oregon & 202 & $22.7(16.8-29.9)$ & & $23.1(17.1-30.5)$ & \\
\hline Georgia & 306 & $24.8(19.3-31.2)$ & & 23.7 (18.5-29.9) & \\
\hline Oklahoma & 197 & $23.8(17.0-32.3)$ & & $24.6(17.3-33.5)$ & \\
\hline Hawaii & 210 & $24.1(17.4-32.3)$ & & $25.9(17.8-36.0)$ & \\
\hline North Dakota & 230 & $26.0(19.5-33.8)$ & & $27.0(20.3-34.9)$ & \\
\hline Maine & 139 & $27.2(19.4-36.6)$ & & $28.1(20.2-37.6)$ & \\
\hline Tennessee & 254 & $27.7(20.8-35.9)$ & & $28.1(21.0-36.5)$ & \\
\hline Arkansas & 278 & $27.9(20.9-36.2)$ & & $29.1(22.3-37.0)$ & \\
\hline Florida & 1,618 & $30.6(25.8-35.8)$ & & $30.0(25.4-35.0)$ & \\
\hline Washington & 378 & $30.6(24.5-37.5)$ & & $30.8(24.5-37.9)$ & \\
\hline Arizona & 170 & $30.7(20.9-42.6)$ & & $32.1(22.2-43.9)$ & \\
\hline Wisconsin & 166 & $31.1(21.2-42.9)$ & & $32.4(22.3-44.4)$ & \\
\hline District of Columbia & 162 & $39.0(28.5-50.8)$ & & $32.7(22.5-44.8)$ & \\
\hline Missouri & 319 & $31.8(24.8-39.7)$ & & $32.8(25.8-40.7)$ & \\
\hline North Carolina & 204 & $32.9(24.5-42.6)$ & & $33.4(24.8-43.2)$ & \\
\hline Mississippi & 426 & $35.5(28.4-43.2)$ & & $34.0(26.8-42.0)$ & \\
\hline South Carolina & 441 & $37.4(31.1-44.1)$ & & $35.8(29.6-42.5)$ & \\
\hline Massachusetts & 112 & $38.9(24.1-56.0)$ & —ף & $37.8(24.8-52.9)$ & —? \\
\hline Nebraska & 291 & $38.9(30.6-47.8)$ & & 39.6 (30.7-49.3) & \\
\hline lowa & 263 & $40.6(33.4-48.1)$ & & $41.7(34.5-49.4)$ & \\
\hline Minnesota & 377 & $43.0(31.5-55.2)$ & & $43.6(31.0-57.1)$ & \\
\hline \multicolumn{6}{|l|}{2013} \\
\hline Total (four states) & 910 & $27.2(23.5-31.3)$ & 0.001 & $27.4(23.5-31.3)$ & 0.0004 \\
\hline Oregon & 202 & $22.7(16.8-29.9)$ & & $22.7(16.2-30.8)$ & \\
\hline Georgia & 306 & $24.8(19.3-31.2)$ & & $24.2(18.8-30.6)$ & \\
\hline Maine & 139 & $27.2(19.4-36.6)$ & & $28.4(20.3-38.2)$ & \\
\hline lowa & 263 & $40.6(33.4-48.1)$ & & 41.7 (34.4-49.4) & \\
\hline \multicolumn{6}{|l|}{2015} \\
\hline Total (four states) & 729 & $35.5(29.6-41.8)$ & 0.033 & $35.5(29.6-41.8)$ & 0.008 \\
\hline Maine & 182 & $28.0(21.0-36.3)$ & & $31.3(23.1-41.0)$ & \\
\hline Georgia & 201 & $34.0(25.4-43.8)$ & & $31.8(24.2-40.6)$ & \\
\hline Oregon & 180 & $36.2(26.8-46.7)$ & & $39.7(29.6-50.8)$ & \\
\hline lowa & 166 & $46.1(37.2-55.3)$ & & $49.8(40.3-59.3)$ & \\
\hline
\end{tabular}

Abbreviation: $\mathrm{Cl}=$ confidence interval.

* Adjusted for age, sex, race/ethnicity, education, insurance status and cardiovascular disease risk factors.

† States are listed in ascending order of adjusted percentages for outpatient stroke rehabilitation in 2013 and 2015.

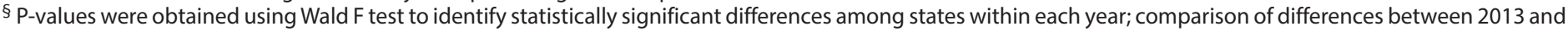
2015 among four states only was $\mathrm{p}=0.0289$.

coordination of care to support assessment, referral, and, ultimately, participation in rehab is needed. The continued underutilization of outpatient stroke rehab might be related to lack of patient access to outpatient facilities, ineffective referral from health care providers, high out-of-pocket costs, lack of health insurance coverage, or lack of knowledge and awareness of benefits of outpatient rehab for stroke survivors $(4,6)$. The CDC-supported Paul Coverdell National Acute Stroke Program ${ }^{\dagger \dagger}$ seeks to better understand the care provided to stroke survivors to identify disparities and support quality improvement around the assessment for, effective referral to,

\footnotetext{
†† The Coverdell program works with health systems across funded recipient states to gather data and drive quality improvement in the prehospital, inhospital, and posthospital care settings. https:/www.cdc.gov/dhdsp/programs/ stroke_registry.htm.
}

and provision of stroke rehab services. Experiences from such programs can support system-level changes that encourage use of stroke rehab services across all subgroups and geographies.

The findings in this report are subject to at least five limitations. First, BRFSS data are self-reported and subject to recall bias. Moreover, recall bias might lead to participants inaccurately reporting the type of stroke rehab they used (i.e., outpatient rehab versus inpatient rehabilitation facilities, skilled nursing facilities, and home health rehab) (10). Second, the survey does not capture stroke severity, variations in rehabilitation needs, or information about why participants did not participate in outpatient rehab. Third, the optional module was only used by selected states, and the findings should not be considered as nationally representative. Fourth, with few respondents reporting a history of stroke (162 in the 


\section{Summary}

What is already known about this topic?

Each year, approximately 800,000 U.S. persons experience a stroke; outpatient stroke rehabilitation use among survivors helps improve outcomes and might reduce stroke recurrences.

What is added by this report?

In 2013,31.2\% of stroke survivors reported participation in outpatient stroke rehabilitation in 20 states and the District of Columbia. Reported use varied by demographic characteristics and by state. Among the four states reporting rehabilitation use for both 2013 (27.7\%) and 2015 (35.5\%), use increased significantly but remained suboptimal.

What are the implications for public health practice?

Implementing strategies that remove barriers and increase use of outpatient stroke rehabilitation among stroke survivors, with special focus among underserved populations, can increase positive health outcomes.

District of Columbia to 1,618 in Florida), some state-level confidence intervals were wide, and results should be interpreted with caution. Finally, only participation in outpatient rehab was included in the module, limiting the ability to assess participation in other rehab modalities.

Although estimates of stroke outpatient rehab referral might be high, participation in stroke outpatient rehab remains suboptimal. Barriers to participation in stroke outpatient rehab are evident $(3,8-10)$, but focused attention on system-level interventions that ensure participation is needed, especially among populations with lower levels of participation. Interventions that might improve outpatient rehab participation include increasing coverage for outpatient rehab services by health insurers, reducing copayments, extending rehab clinic hours to improve access availability, and implementing standardized assessments by health care professionals to guide appropriate referrals to outpatient rehab at hospital discharge $(3-5,8)$. Stroke survivors should be educated about stroke outpatient rehab opportunities possibly available in their community that reduce barriers related to transportation and time (e.g., telehealth, mobileHealth, and home-based care) $(3,5,6,8-10)$.

\section{Conflict of Interest}

No conflicts of interest were reported.

\footnotetext{
${ }^{1}$ Division for Heart Disease and Stroke Prevention, National Center for Chronic Disease Prevention and Health Promotion, CDC.

Corresponding author: Carma Ayala, cayala@cdc.gov, 770-488-8072.
}

\section{References}

1. Xu J, Murphy SL, Kochanek KD, et al. Mortality in the United States, 2015. NCHS data brief no. 267. Hyattsville, MD: US Department of Health and Human Services, CDC, National Center for Health Statistics; 2016. https:// www.cdc.gov/nchs/data/databriefs/db267.pdf

2. Benjamin EJ, Blaha MJ, Chiuve SE, et al.; American Heart Association Statistics Committee and Stroke Statistics Subcommittee. Heart disease and stroke statistics-2017 update: a report from the American Heart Association. Circulation 2017;135:e146-603. https://doi.org/10.1161/ CIR.0000000000000485

3. Winstein CJ, Stein J, Arena R, et al.; American Heart Association Stroke Council, Council on Cardiovascular and Stroke Nursing, Council on Clinical Cardiology, and Council on Quality of Care and Outcomes Research. Guidelines for adult stroke rehabilitation and recovery: a guideline for healthcare professionals from the American Heart Association/American Stroke Association. Stroke 2016;47:e98-169. https://doi.org/10.1161/ STR.0000000000000098

4. Prvu Bettger JA, Kaltenbach L, Reeves MJ, et al. Assessing stroke patients for rehabilitation during the acute hospitalization: findings from the get with the guidelines-stroke program. Arch Phys Med Rehabil 2013;94:38-45. https://doi.org/10.1016/j.apmr.2012.06.029

5. Ovbiagele B, Goldstein LB, Higashida RT, et al.; American Heart Association Advocacy Coordinating Committee and Stroke Council. Forecasting the future of stroke in the United States: a policy statement from the American Heart Association and American Stroke Association. Stroke 2013;44:2361-75. https://doi.org/10.1161/STR.0b013e31829734f2

6. Huckfeldt PJ, Mehrotra A, Hussey PS. The relative importance of post-acute care and readmissions for post-discharge spending. Health Serv Res 2016;51:1919-38. https://doi.org/10.1111/1475-6773.12448

7. Xie J, George M, Ayala C, et al. Outpatient rehabilitation among stroke survivors-21 states and the District of Columbia, 2005. MMWR Morb Mortal Wkly Rep 2007;56:504-7.

8. Iyer M, Bhavsar GP, Bennett KJ, Probst JC. Disparities in home health service providers among Medicare beneficiaries with stroke. Home Health Care Serv Q 2016;35:25-38. https://doi.org/10.1080/01621424.2016.1175991

9. Skolarus LE, Feng C, Burke JF. No racial difference in rehabilitation therapy across all post-acute care settings in the year following a stroke. Stroke 2017;48:3329-35. https://doi.org/10.1161/STROKEAHA.117.017290

10. Skolarus LE, Freedman VA, Feng C, Wing JJ, Burke JF. Care received by elderly US stroke survivors may be underestimated. Stroke 2016;47:2090-5. https://doi.org/10.1161/STROKEAHA.116.012704 